\title{
Herd- and Cow-Level Prevalence of Foot Lesions in Ontario Dairy Cattle
}

\author{
G. Cramer, ${ }^{* 1}$ K. D. Lissemore, ${ }^{*}$ C. L. Guard, $†$ K. E. Leslie, ${ }^{*}$ and D. F. Kelton* \\ *Department of Population Medicine, Ontario Veterinary College, University of Guelph, Ontario, N1G 2W1 Canada \\ †Department of Population Medicine and Diagnostic Sciences, College of Veterinary Medicine, Cornell University, Ithaca, NY 14853
}

\begin{abstract}
The objectives of this cross-sectional study were to determine herd-level and cow-level prevalence estimates for 11 foot lesions in Ontario dairy cattle. Foot lesions were recorded by 5 hoof trimmers on 13,530 cows in 204 Ontario dairy herds from March 2004 to May 2005. Significant differences existed between free-stall and tie-stall housing. In free-stall housing systems, $46.4 \%$ of cows had a foot lesion, compared with $25.7 \%$ of cows in tie-stall barns. Digital dermatitis was the most common lesion in tie stalls, occurring in $9.3 \%$ of cows and $69.7 \%$ of the herds, whereas in free-stall herds, $22.7 \%$ of cows and $96.7 \%$ of the herds were affected. The most common hoof horn lesions were hemorrhages and ulcers, at 7.7 and $4.7 \%$ in tie-stall housing and 11.0 and $9.2 \%$ in free-stall housing, respectively. Foot blocks were used to treat $2.2 \%$ of cows in free stalls and $0.3 \%$ in tie stalls. Intraclass correlation coefficients ranged from 9.5 to 17.3 for hoof horn lesions and 28.0 to 38.7 for infectious lesions. In summary, foot lesions diagnosed at the time of hoof trimming are common in Ontario, and appropriate treatment for hoof horn lesions is low.
\end{abstract}

Key words: foot lesion, prevalence, tie stall, free stall

\section{INTRODUCTION}

Lameness is a painful (Whay et al., 1998), costly disease that affects the productivity of cows through its effect on milk production (Warnick et al., 2001; Green et al., 2002), culling (Booth et al., 2004), and reproductive performance (Barkema et al., 1994; Melendez et al., 2003). In addition, lameness is a highly visible disease. As such, lameness should be considered one of the major animal welfare issues in the dairy industry. In response to the potential for lameness as an animal welfare issue, lameness as measured by locomotion scoring has been a component of several welfare audits (Whay et al., 2003; Stull et al., 2004).

Received February 28, 2008.

Accepted June 5, 2008.

${ }^{1}$ Corresponding author: gerard@mecnrec.ca
The majority of lameness cases are due to lesions on the foot (Murray et al., 1996). Therefore, regular monitoring of lesions at the hoof level (Mills et al., 1986; Guard, 2001) allows for earlier interventions by producers and their advisors (Noordhuizen, 2003; Shearer et al., 2004). Through the use of earlier interventions, the number of severe lameness cases should decrease, and in turn, animal well-being should improve. To regularly monitor disease in herds, a standardized case definition (Kelton et al., 1998) and a target level at which diagnostic or corrective action is taken (Radostits, 2001) are required. In North America, these data have been generated for use in monitoring lameness through locomotion scoring (Cook, 2003; Espejo et al., 2006). Similar monitoring data have not been reported for foot lesions. Nevertheless, in several countries in Europe, the foot lesion data for these target levels have been generated (Manske et al., 2002; Sogstad et al., 2005; Holzhauer et al., 2006). Yet given the difference in breeds, management, feeding, and environments among countries, it is unclear whether data from these studies are applicable to Ontario or other North American conditions.

Considering the lack of current information on foot lesion prevalence data, a 15-mo project was designed to describe the state of foot health in Ontario dairy cows. The objective was to describe the cow- and herd-level prevalence, as well as the within-herd variance components, of foot lesions in Ontario dairy cattle.

\section{MATERIALS AND METHODS}

\section{Study Design}

The target population for this cross-sectional study consisted of all Ontario dairy cattle. The study population was drawn from this target population, and 5 professional hoof trimmers (HT) were used, to obtain a convenience sample from March 2004 through May 2005. The $5 \mathrm{HT}$ were recruited via a mailing to $30 \mathrm{HT}$ that advertised in dairy industry magazines or were listed in a provincial database. Twelve HT replied to the initial request and 7 attended a training session in March 2004. Of the 7 attendees, 5 decided to participate in the project. 
Table 1. Definition of codes and lesions provided to hoof trimmers on standardized recording sheet

\begin{tabular}{|c|c|c|}
\hline Code & Lesion name (alternative common names) & Definition \\
\hline $\mathrm{D}$ & $\begin{array}{l}\text { Digital dermatitis (Mortellaro's disease, } \\
\text { strawberry foot rot, hairy heel warts) }\end{array}$ & $\begin{array}{l}\text { Sore, raw, sometimes hairy area on the skin around the heels and } \\
\text { between the hooves. Can have a white rim around the lesion. }\end{array}$ \\
\hline $\mathrm{F}$ & $\begin{array}{l}\text { Foot rot (interdigital phlegmon, } \\
\text { foul in the foot) }\end{array}$ & $\begin{array}{l}\text { Symmetrical swelling above the hooves, with spreading of the toes. } \\
\text { Usually accompanied by cracked, dead, smelly skin between the digits. }\end{array}$ \\
\hline $\mathrm{H}$ & Hemorrhage (bruising, laminitis) & Red or yellow discoloration of the sole or white line. \\
\hline $\mathrm{T}$ & Thin soles & Cow has a toe length $<3$ in. $(7.5 \mathrm{~cm})$ when measured from the coronary band. \\
\hline $\mathrm{U}$ & Ulcer & $\begin{array}{l}\text { Defect in the sole horn that exposes the corium; can be } \\
\text { accompanied by granulation tissue. Typically occurs on the } \\
\text { inner side of the sole, but can occur in the toe or heel. }\end{array}$ \\
\hline $\mathrm{V}$ & Vertical wall crack & Vertical split in the wall, usually starting at the junction of the wall and skin. \\
\hline $\mathrm{N}$ & Nonfoot lesion & $\begin{array}{l}\text { Cow is lame, but no lesions were found in or on the foot, and } \\
\text { it has another cause of lameness (swollen hock). }\end{array}$ \\
\hline $\mathrm{X}$ & Lame & Cow is noticeably lame when walking or standing. \\
\hline
\end{tabular}

During the training session, the HT were trained in standardized lesion identification and completed 2 lesion identification quizzes, 1 before training and 1 after training. To ensure that lesion identification remained consistent throughout the $15 \mathrm{mo}$, HT were provided with a lesion identification chart and descriptions for future reference. At the conclusion of the project, the HT completed another lesion identification quiz. Hoof trimmers were provided with carbon-copy lesion recording sheets and were asked to record all lesions on all cows that were trimmed. Selection of the cows for trimming was at the discretion of the producer. No attempt was made to select cows based on trimming history, lactation status, or any other criteria. In addition to recording lesion data, HT completed a 3-page questionnaire for each farm during the study period (Cramer, 2007).

Hoof trimmers identified the presence of foot lesions and applicable treatments by using the criteria described in Table 1. The foot lesion nomenclature was based on a proposal by the American Association of Bovine Practitioners' Lameness Committee (Shearer et al., 2004). Hoof trimmers recorded foot lesion data on a form that was based on the forms used by most of the participating HT.

The questionnaire was used to collect descriptive data for this study and for a later herd-level risk factor study. The questionnaire included general questions on housing, feeding, and hoof health management; details of the questionnaire are presented elsewhere (Cramer, 2007). At the conclusion of the project, several herds had lesion information recorded but had no corresponding questionnaire data. Managers of these herds were contacted and asked to complete the questionnaire by mail.

\section{Data Management and Statistical Analysis}

Both questionnaire and lesion data were entered into a database (MySQL 4.1, MySQL AB, Uppsala, 
Sweden) via the Internet. Data management and descriptive analysis were done with Microsoft Excel and a commercially available statistical program (Stata 9.1, StataCorp, College Station, TX). Individual cows with duplicate, unreadable, or missing cow identification were removed from the data set.

For each type of foot lesion, prevalence was calculated as the number of affected animals divided by the number examined. Data on lesions at the foot level were collapsed first into front and hind limbs and then into cow. A cow was considered affected if one hoof had a lesion present. Only the first occurrence of a cow in the data set was used to calculate lesion prevalence at the cow and herd level. For each foot lesion, the difference in prevalence between free-stall and tie-stall housing types was compared with a chi-squared test at the cow level and with a Mann-Whitney test at the herd level.

Before the foot lesion data were collapsed into cow lesion data, the data structure had 4 different levels: HT, within-HT herds, within-herd cows, and withincow feet. Data were recorded at the lowest level (foot) on a binary scale. For variance component analysis, intraclass correlation coefficients (ICC) were calculated at the herd level in Stata 9.1 by using a random effect generalized linear mixed model with a binomial distribution and a logit link. In Stata, this was accomplished by using the generalized linear and latent mixed model procedure. This procedure used adaptive quadrature to determine the maximum likelihood estimates. The generalized linear and latent mixed model was fitted without restrictions on the number of iterations.

All variance component models contained only cows housed in tie-stall or free-stall herds because of meager data in the other housing categories. In addition, these models contained both HT and housing type as fixed effects. Furthermore, the models were stratified according to HT for each lesion to allow for comparisons between HT.

To estimate the variance components from the model, the following equation was used:

$$
\operatorname{Var}(\mathrm{Z})=\operatorname{var}(\text { herd })+\operatorname{var}(\text { error }),
$$

where $\operatorname{var}(\mathrm{Z})$ is the total variation of the model, $\operatorname{var}($ herd) is the variance of the herd random effects, and var(error) is $\Pi^{2} / 3$ because an underlying latent logistic distribution is assumed (Dohoo et al., 2003). From these variance components, an ICC was calculated by using the following equation:

$$
\text { Herd ICC }=\sigma^{2}(\text { herd }) /\left[\sigma^{2}(\text { herd })+\Pi^{2} / 3\right] .
$$

Herd ICC represent within-herd correlations. A herd ICC of 0 means that there is no correlation between animals of the same herd and an ICC of 1.0 means a perfect correlation between animals (Holzhauer et al., 2006).

Cohen's kappa was used to calculate the level of agreement beyond chance between HT for each foot lesion from the lesion identification quizzes (Dohoo et al., 2003) to evaluate the agreement between HT. To further investigate the potential of misclassification bias, ICC were compared between HT.

\section{RESULTS}

Hoof trimmers recorded lesions on 13,530 individual cows in 204 herds. The data were collected over a 15mo time period, and 93 herds and 3,967 cows had data from multiple trimmings. Hoof trimmers completed 146 questionnaires at the time of hoof trimming and failed to complete questionnaires on 59 herds. Thirty-nine of the missing questionnaires were completed by producers and returned by mail. Thirty-eight herds used freestall housing, 142 herds used tie-stall housing, 3 herds used a combination of the 2 , and 1 herd used a bedded pack. Housing information was not available from the remaining 20 herds. Because of the low number of other housing systems, the results presented here are restricted to tie-stall and free-stall herds.

Average herd size and 305-d milk production for the 157 herds enrolled in DHI was 86 [95\% confidence interval (CI): 62 to 112] and 9,254 kg (CI: 8,938 to 9,571 $\mathrm{kg}$ ), respectively, for free-stall herds and 42 (CI: 39 to 44) and 9,179 kg (CI: 8,973 to 9,385), respectively, for tie-stall herds. Herd size for herds not enrolled in DHI was not significantly different from herds using DHI services.

Tables 2 and 3 present the cow- and herd-level prevalence for tie stalls and free stalls, respectively. Cow-level prevalence is presented for the first hoof trimming in the data set. Mean herd-level prevalence is presented for the first hoof trimming date for each herd. Infectious lesions were the most common in both types of housing systems, with digital dermatitis as the most common lesion overall. In both housing systems, back feet had a greater lesion prevalence than did front feet. Herd prevalence varied, yet for most lesions, there were herds that had a prevalence of zero.

There was a difference $(P<0.05)$ in herd-level prevalence between tie-stall and free-stall housing for all lesions except for foot rot (0 vs. $0.3 \%$ ), heel horn erosion (10.2 vs. $12.1 \%)$, and deep sepsis (0 vs. $0.5 \%)$. At the cow level, there was a difference $(P<0.05)$ between housing types for all lesions except for foot rot (0.2 vs. $0.2 \%$ ) and heel horn erosion (8.3 vs. $8.4 \%$ ).

Average between-HT kappa from the lesion identification quizzes are shown in Table 4. Even though quiz 
Table 2. Herd- and cow-level prevalence (\%) of foot lesions in 142 tie-stall herds as recorded by 5 professional hoof trimmers from March 2004 to May 2005

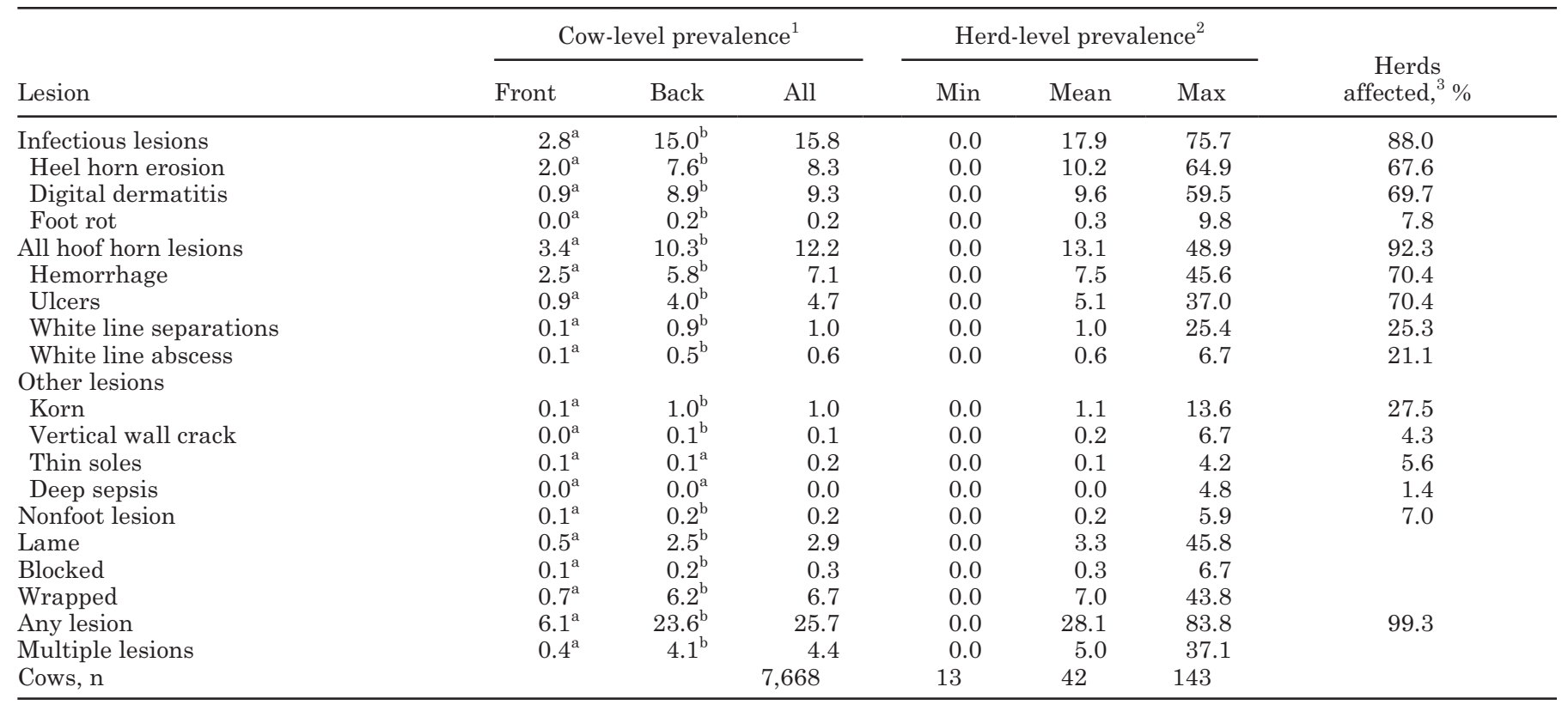

${ }^{\mathrm{a}, \mathrm{b}}$ Prevalences within a row with different superscripts differ $(P<0.05)$.

${ }^{1}$ Cow-level prevalence $(\%)=\mathrm{n}$ cows with a lesion/n cows examined. Subdivided into front, back legs and all 4 legs combined.

${ }^{2}$ Herd-level prevalence $(\%)=\mathrm{n}$ cows in the herd with a lesion/n cows examined in the herd. Subdivided into minimum, mean, and maximum herd-level prevalence for 142 herds.

${ }^{3}$ Percentage of herd affected was calculated as the number of herds with at least 1 animal affected/total number of herds.

Table 3. Herd- and cow-level prevalence (\%) of foot lesions in 38 free-stall herds as recorded by 5 professional hoof trimmers from March 2004 to May 2005

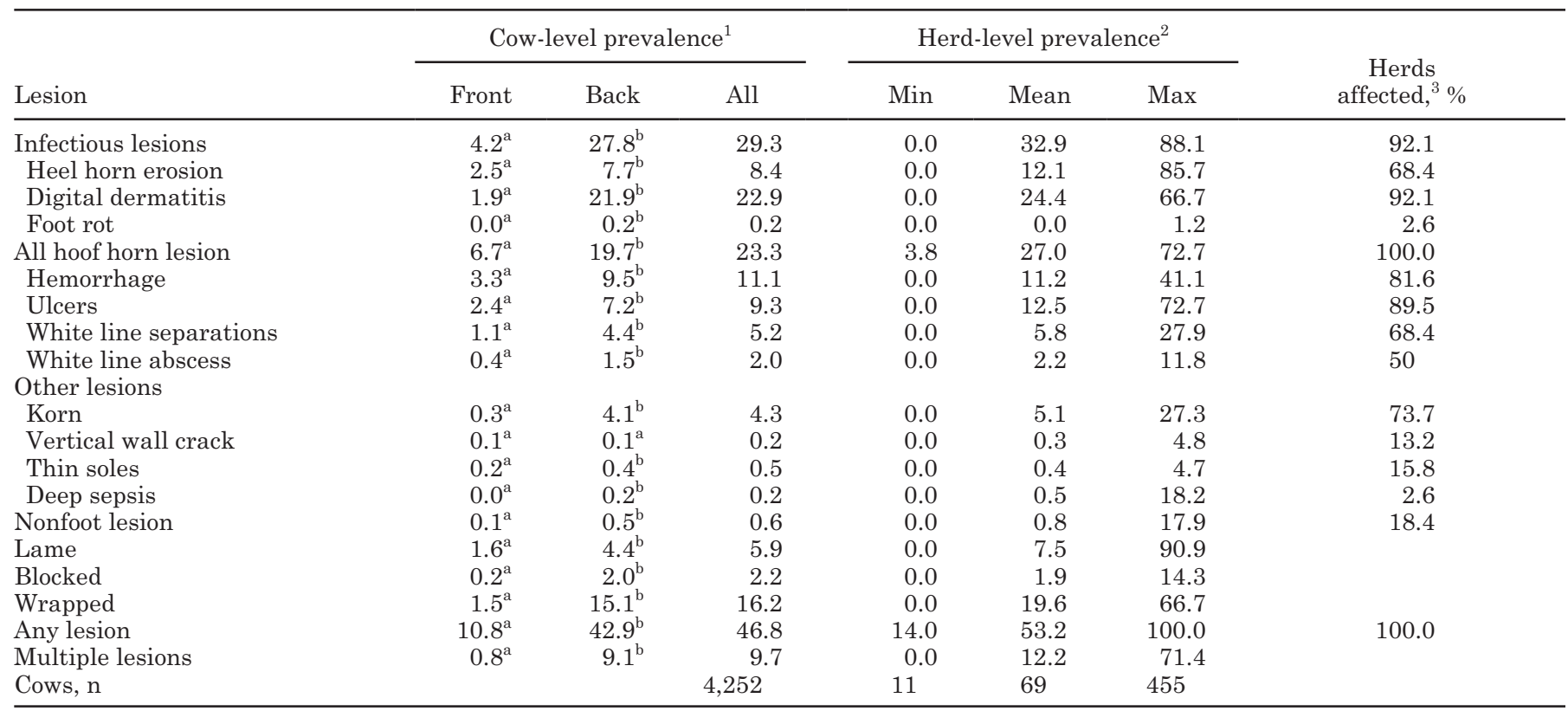

${ }^{\mathrm{a}, \mathrm{b}}$ Prevalences within a row with different superscripts differ $(P<0.05)$.

${ }^{1}$ Cow-level prevalence $(\%)=\mathrm{n}$ cows with a lesion/n cows examined. Subdivided into front, back legs and all 4 legs combined.

${ }^{2}$ Herd-level prevalence $(\%)=\mathrm{n}$ cows in the herd with a lesion/n cows examined in the herd. Subdivided into minimum, mean, and maximum herd-level prevalence for 39 herds.

${ }^{3}$ Percentage of herd affected was calculated as the number of herds with at least 1 animal affected/total number of herds. 
Table 4. Average level of agreement beyond chance, as measured by Cohen's kappa, between hoof trimmers for each foot lesion from 3 different lesion identification quizzes

\begin{tabular}{lccc}
\hline & \multicolumn{3}{c}{ Quiz number $^{2}$} \\
\cline { 2 - 4 } Foot lesion $^{1}$ & 1 & 2 & 3 \\
\hline Digital dermatitis & $0.47^{3}$ & 0.30 & 1.00 \\
Heel horn erosion & 0.22 & 0.10 & 1.00 \\
Foot rot & 0.35 & 0.10 & 0.63 \\
White line abscess & 0.21 & 0.48 & 1.00 \\
White line separation & 0.56 & 0.21 & 1.00 \\
Hemorrhage & 0.34 & 0.13 & 1.00 \\
Ulcer & 0.55 & 0.36 & 1.00 \\
Korn & 0.64 & 0.63 & 0.63 \\
Vertical wall crack & 0.58 & 0.48 & $\mathrm{NA}$ \\
Normal & 0.00 & 0.30 & 1.00 \\
Nonfoot lesion & 0.00 & 0.90 & 1.00 \\
\hline
\end{tabular}

${ }^{1}$ Lesions were identified from digital photographs projected onto a large screen.

${ }^{2}$ Quizzes 1 and 2 were done at the onset of the project, and quiz 3 was completed at the end of the project.

${ }^{3}$ Interpretation: kappa values $<0.2=$ slight agreement, 0.2 to $0.4=$ fair agreement, 0.4 to $0.6=$ moderate agreement, 0.6 to $0.8=$ substantial agreement, $>0.8=$ almost perfect agreement.

${ }^{4} \mathrm{NA}=$ lesion not included in the quiz.

2 was completed after the training session, the kappa statistic for 7 of the 10 foot lesions actually decreased. Numerical ratings for quizzes 1,2 , and 3 were 65,71 , and $94 \%$, respectively. Substantial to perfect agreement existed between HT for quiz 3. Within-herd ICC are given in Table 5. Most herd ICC showed variation between HT, but only 1 HT (HT 4) had consistently low ICC for 7 of the 9 lesions.

\section{DISCUSSION}

Compared with Ontario industry averages, the herds participating were smaller in size and produced $1,000 \mathrm{~kg}$ more milk per cow (CanWest DHI, 2006). The percentage of herds using free-stall housing (22\%) was close to the Ontario average (25\%; CanWest DHI, 2006). The greater milk production of the farms compared with the provincial average was possibly due to only 2 major breeds being represented in the data set. Alternatively, it is possible that the use of hoof trimming on a regular basis is an indicator of a higher management level. Even though there were differences between the study herds and the average Ontario herd, the study herds should be considered representative of Ontario herds that use professional hoof trimming and were on a routine hoof-trimming schedule.

\section{Prevalence of Foot Lesions}

Comparing herd- and cow-level prevalence estimates of foot lesions from this study with the results of other studies was difficult because of the differences in foot lesion scoring systems and overall herd management styles. This study is the first report of foot lesion prevalence estimates across multiple herds and management styles for anywhere in North America. Most North American studies have reported lameness prevalence or foot lesion prevalence for lame cows only (Cook, 2003; Melendez et al., 2003; Booth et al., 2004).

The prevalence estimates of foot lesions showed a greater prevalence than in Norway (Sogstad et al., 2005), a lesser prevalence than in Sweden (Manske et al., 2002) and a prevalence similar to the Netherlands (Holzhauer et al., 2006). The Dutch research was similar in study design to the current study, but the Dutch work included only free-stall herds. The greater prevalence reported for free-stall herds was consistent with other studies (Manske et al., 2002; Sogstad et al., 2005).

Similar to other studies (Somers et al., 2003; Holzhauer et al., 2006), infectious lesions were the most prevalent in both housing systems. This finding raises questions about the efficacy, implementation, or management of current recommended therapies. Unlike in the study by Sogstad et al. (2005), the prevalence of heel horn erosion was relatively consistent across housing types. This was somewhat surprising because moisture and manure are known risk factors (Toussaint Raven et al., 1985) for heel horn erosion, and exposure to these factors was greater in most free-stall barns. The prevalence of digital dermatitis was consistent with other reports (Somers et al., 2003; Holzhauer et al., 2006) that have illustrated the difficulty of producers in managing the disease in spite of relatively effective therapies and control strategies (Laven and Logue, 2006). The greater prevalence of digital dermatitis in free stalls (22.9 vs. 9.3\%) reflects the increased exposure these cows would have to manure and moisture.

The recording of sole hemorrhages $(11.0 \%$ for freestall barns and $7.1 \%$ for tie-stall barns) in was relatively subjective. Other reports required HT to judge the size of the area affected (Holzhauer et al., 2006). Therefore, it was likely that the lesser prevalence estimate was an assessment of the prevalence of severe sole hemorrhages and did not include minor discoloration of the sole. This is supported by the prevalence estimates for ulcers $(9.3 \%$ in free stalls and $4.7 \%$ in tie stalls), white line separations $(5.2 \%$ in free stalls and $1.0 \%$ in tie stalls), and white line abscess $(2.0 \%$ in free stalls and $0.6 \%$ in tie stalls), which were similar to the estimates of others (Manske et al., 2002; Sogstad et al., 2005; Holzhauer et al., 2006), and these foot lesions were considered gradients of a similar disease process (Leach et al., 1998; Lischer et al., 2002). 
Table 5. Comparison of within-herd intraclass correlation coefficients (expressed as \%) between hoof trimmers (HT)

\begin{tabular}{|c|c|c|c|c|c|c|}
\hline Item & All herds & HT 0 & HT 1 & HT 2 & HT 3 & HT 4 \\
\hline Herds, $n$ & 180 & 72 & 30 & 34 & 38 & 6 \\
\hline Digital dermatitis & 33.3 & 41.4 & 33.8 & 23.2 & 29.1 & 19.2 \\
\hline Foot rot & 38.7 & $\mathrm{NA}^{1}$ & NA & NA & NA & NA \\
\hline Hoof horn lesions & 10.1 & 9.1 & 10.2 & 9.2 & 11.7 & 3.5 \\
\hline White line separations & 12.6 & 12.2 & 0.0 & 4.8 & 6.8 & 3.1 \\
\hline White line abscess & 13.4 & 19.0 & 15.7 & 0.0 & 13.2 & 0.0 \\
\hline \multicolumn{7}{|l|}{ Other lesions } \\
\hline Korn & 24.1 & NA & NA & NA & NA & NA \\
\hline Vertical wall crack & 8.2 & NA & NA & NA & NA & NA \\
\hline Thin soles & 18.8 & NA & NA & NA & NA & NA \\
\hline Any lesion & 14.0 & 11.8 & 19.2 & 15.6 & 13.3 & 6.1 \\
\hline
\end{tabular}

${ }^{1} \mathrm{NA}=$ not enough cows affected with the lesion to calculate an intraclass correlation coefficient.

Considering that lameness is a painful, long-lasting condition (Whay et al., 1998), it is surprising that only a few cows $(2.2 \%$ in free stalls and $0.3 \%$ in tie stalls) were treated with the use of a block. Reduced pressure on the affected hoof through the application of a block to the sound hoof is considered standard therapy for cows with sole ulcers or white line abscesses (Toussaint Raven et al., 1985). Alternative treatment strategies exist if enough heel is present on the sound hoof (Manabe et al., 2004). Nevertheless, it is likely that this method was not widely adopted because of the novelty of the technique. From the data, it is unclear what percentage of cows would have been considered lame and in need of a block. An attempt was made to capture these data, but it was only sporadically recorded. It is likely that with a prevalence of $11.3 \%$ combined for ulcers and white line abscesses in free-stall herds, more than $20 \%$ of these cows would have received substantial benefit from a block applied to the sound hoof. It is unclear whether the decision to place a block on a cow rests with the producer or with the HT at the time of trimming. Either way, it is likely that the cost of the block and its application decreased their use.

\section{Effect of HT}

The use of professional HT to record lesions was a potential source of misclassification bias (Sogstad et al., 2005; Holzhauer et al., 2006). To address this source of bias, HT were trained and evaluated by using digital photos at the beginning and end of the project. Although numerical grades for individual quizzes increased after the training session, the kappa statistic for some lesions actually decreased. This decrease showed that for individual HT, lesion recognition improved but that there was still a lack of agreement between HT. It was not possible to detect trends in HT lesion recognition improvement because of constraints in the number of pictures that were part of the lesion identification quizzes.

Kappa measures the extent of agreement beyond what would have been expected by chance. Some guidelines for interpreting kappa have been proposed (Dohoo et al., 2003). When these guidelines were used, the kappa values ranged from slight to substantial agreement for quizzes 1 and 2 . At the conclusion (quiz 3), agreement among HT was excellent for all lesions. This high level of agreement was unexpected, especially because 11 veterinarians completed the same quiz and had slight to moderate agreement (Cramer, 2007).

The range in kappa values reported was similar to the values recorded in the Netherlands (Holzhauer et al., 2006), yet these values were lower than those in a Swedish study (Manske et al., 2002) that used a more intense degree of training. In the future, given that digital photos are only 2-dimensional and do not truly represent working conditions, a more appropriate assessment tool may be the use of live animals (Holzhauer et al., 2006).

The conflicting results obtained for lesion scoring after the training sessions were further explored by evaluating the effect of HT on herd ICC. From the ICC presented, one HT had lower ICC for lesions. Because of the low number of herds this HT contributed to the study, the effect on the whole study was likely small. Variation in the herd ICC between HT could be due to 
HT and other uncontrolled herd-level variables. Cowlevel variation was fixed at $\Pi^{2} / 3$ and would therefore not be a significant source of variation.

Based on the kappa values and herd ICC, the HT appears to be a source of misclassification bias. This finding was consistent with a Dutch study that reported high ICC for HT for sole hemorrhage, interdigital heel horn erosion, and chronic laminitis (Holzhauer et al., 2006). The present study only used a small number of $\mathrm{HT}$, and it was not possible to determine ICC for HT to further evaluate this misclassification bias.

\section{CONCLUSIONS}

Significant differences existed in prevalence estimates between free-stall and tie-stall housing. In tie stalls, $26 \%$ of cows had a foot lesion compared with $47 \%$ in free stalls. Infectious lesions were most common in both housing systems $(29.3 \%$ in free stalls and $15.8 \%$ in tie stalls), and the majority of herds had cows affected with at least 1 lesion. Given that the future of the dairy industry appears to be free-stall housing, there is a need for herd-level studies that identify risk factors that can be managed to improve the welfare of dairy cows. In addition, there is a need to determine the effect of these hoof lesions on productivity.

\section{ACKNOWLEDGMENTS}

Funding for this project was provided by the Dairy Farmers of Ontario (Mississauga, Ontario, Canada), American Association of Bovine Practitioners (Auburn, AL), Ontario Ministry of Agriculture, Food and Rural Affairs (Guelph, Ontario, Canada), Natural Science and Engineering Research Council (Ottawa, Ontario, Canada), and the Hoof Trimmers Association (Missoula, MT). We are grateful for the assistance provided by the participating hoof trimmers and Janyk Laferrière.

\section{REFERENCES}

Barkema, H. W., J. D. Westrik, K. A. S. Van Keulen, Y. H. Schukken, and A. Brand. 1994. The effects of lameness on reproductive performance, milk production and culling in Dutch dairy farms. Prev. Vet. Med. 20:249-259.

Booth, C. J., L. D. Warnick, Y. T. Grohn, D. O. Maizon, C. L. Guard, and D. Janssen. 2004. Effect of lameness on culling in dairy cows. J. Dairy Sci. 87:4115-4122.

CanWest DHI. 2006. 2005 Ontario DHI Progress Report. CanWest DHI, Guelph, Ontario, Canada.

Cook, N. B. 2003. Prevalence of lameness among dairy cattle in Wisconsin as a function of housing type and stall surface. J. Am. Vet. Med. Assoc. 223:1324-1328.

Cramer, G. 2007. Quantification of foot lesions and an evaluation of early detection methods for lameness in Ontario dairy farms. DVSc Thesis. The University of Guelph, Guelph, Ontario, Canada.
Dohoo, I. R., W. Martin, and H. Stryhn. 2003. Veterinary Epidemiologic Research. University of Prince Edward Island, Charlottetown, Prince Edward Island, Canada.

Espejo, L. A., M. I. Endres, and J. A. Salfer. 2006. Prevalence of lameness in high-producing Holstein cows housed in freestall barns in Minnesota. J. Dairy Sci. 89:3052-3058.

Green, L. E., V. J. Hedges, Y. H. Schukken, R. W. Blowey, and A. J. Packington. 2002. The impact of clinical lameness on the milk yield of dairy cows. J. Dairy Sci. 85:2250-2256.

Guard, C. 2001. Investigating herds with lameness problems. Vet. Clin. North Am. Food Anim. Pract. 17:175-187.

Holzhauer, M., C. J. Bartels, B. H. van den Borne, and G. van Schaik. 2006. Intra-class correlation attributable to claw trimmers scoring common hind-claw disorders in Dutch dairy herds. Prev. Vet. Med. 75:47-55.

Kelton, D. F., K. D. Lissemore, and R. E. Martin. 1998. Recommendations for recording and calculating the incidence of selected clinical diseases of dairy cattle. J. Dairy Sci. 81:25022509

Laven, R. A., and D. N. Logue. 2006. Treatment strategies for digital dermatitis for the UK. Vet. J. 171:79-88.

Leach, K. A., D. N. Logue, J. M. Randall, and S. A. Kempson. 1998. Claw lesions in dairy cattle: Methods for assessment of sole and white line lesions. Vet. J. 155:91-102.

Lischer, Ch. J., P. Ossent, M. Räber, and H. Geyer. 2002. Suspensory structures and supporting tissues of the third phalanx of cows and their relevance to the development of typical sole ulcers (Rusterholz ulcers). Vet. Rec. 151:694-698.

Manabe, H., Y. Kazunori, and I. Ryouichi. 2004. Magic formula of heel-less technique. Pages 108-110 in Proc. 13th Int. Symp. 5th Conf. Lameness Rumin., Maribor, Slovenija. Ungula, Zemljic and Co., Ormoz, Slovenija.

Manske, T., J. Hultgren, and C. Bergsten. 2002. Prevalence and interrelationships of hoof lesions and lameness in Swedish dairy cows. Prev. Vet. Med. 54:247-263.

Melendez, P., J. Bartolome, L. E. Archbald, and A. Donovan. 2003. The association between lameness, ovarian cysts and fertility in lactating dairy cows. Theriogenology 59:927-937.

Mills, L. L., D. H. Leach, M. E. Smart, and P. R. Greenough. 1986. A system for the recording of clinical data as an aid in the diagnosis of bovine digital disease. Can. Vet. J. 27:293-300.

Murray, R. D., D. Y. Downham, M. J. Clarkson, W. B. Faull, J. W Hughes, F. J. Manson, J. B. Merritt, W. B. Russell, J. E. Sutherst, and W. R. Ward. 1996. Epidemiology of lameness in dairy cattle: Description and analysis of foot lesions. Vet. Rec. 138:586-591.

Noordhuizen, J. P. T. M. 2003. Veterinary herd health and production advisory programmes for dairy farms: Developments and prospects. Cattle Pract. 11:209-216.

Radostits, O. M. 2001. Herd Health: Food Animal Production Medicine. Saunders, Philadelphia, PA.

Shearer, J., D. Anderson, W. Ayars, E. Belknap, S. Berry, C. Guard, K. Hoblet, E. Hovingh, G. Kirksey, A. Langill, A. Mills, D. Miskimins, J. Osterstock, R. Price, D. Prigel, A. Roussel, S. v. Amstel, R. Wallace, J. Wasson, N. Cook, E. F. Garrett, D. E. Hostetler, and L. Schugel. 2004. A record keeping system for capture of lameness and foot-care information in cattle. Bovine Pract. 38:83-91.

Sogstad, A. M., T. Fjeldaas, O. Osteras, and K. P. Forshell. 2005 Prevalence of claw lesions in Norwegian dairy cattle housed in tie stalls and free stalls. Prev. Vet. Med. 70:191-209.

Somers, J. G., K. Frankena, E. N. Noordhuizen-Stassen, and J. H. Metz. 2003. Prevalence of claw disorders in Dutch dairy cows exposed to several floor systems. J. Dairy Sci. 86:2082-2093.

Stull, C. L., S. L. Berry, B. A. Reed, and M. A. Payne. 2004. Dairy Welfare Evaluation Guide. Cooperative Extension, Univ. of California, Davis. http://www.cdqa.org/ahw/index.htm Accessed April 5, 2005.

Toussaint Raven, E., R. T. Haalstra, and D. J. Peterse. 1985. Cattle Footcare and Claw Trimming. Farming Press, Ipswich, Suffolk. UK. 
Warnick, L. D., D. Janssen, C. L. Guard, and Y. T. Grohn. 2001. The effect of lameness on milk production in dairy cows. J. Dairy Sci. 84:1988-1997.

Whay, H. R., D. C. J. Main, L. E. Green, and A. J. F. Webster. 2003. Animal-based measures for the assessment of welfare state of dairy cattle, pigs and laying hens: Consensus of expert opinion. Anim. Welf. 12:205-217.
Whay, H. R., A. E. Waterman, A. J. Webster, and J. K. O'Brien. 1998. The influence of lesion type on the duration of hyperalgesia associated with hindlimb lameness in dairy cattle. Vet. J. $156: 23-29$. 